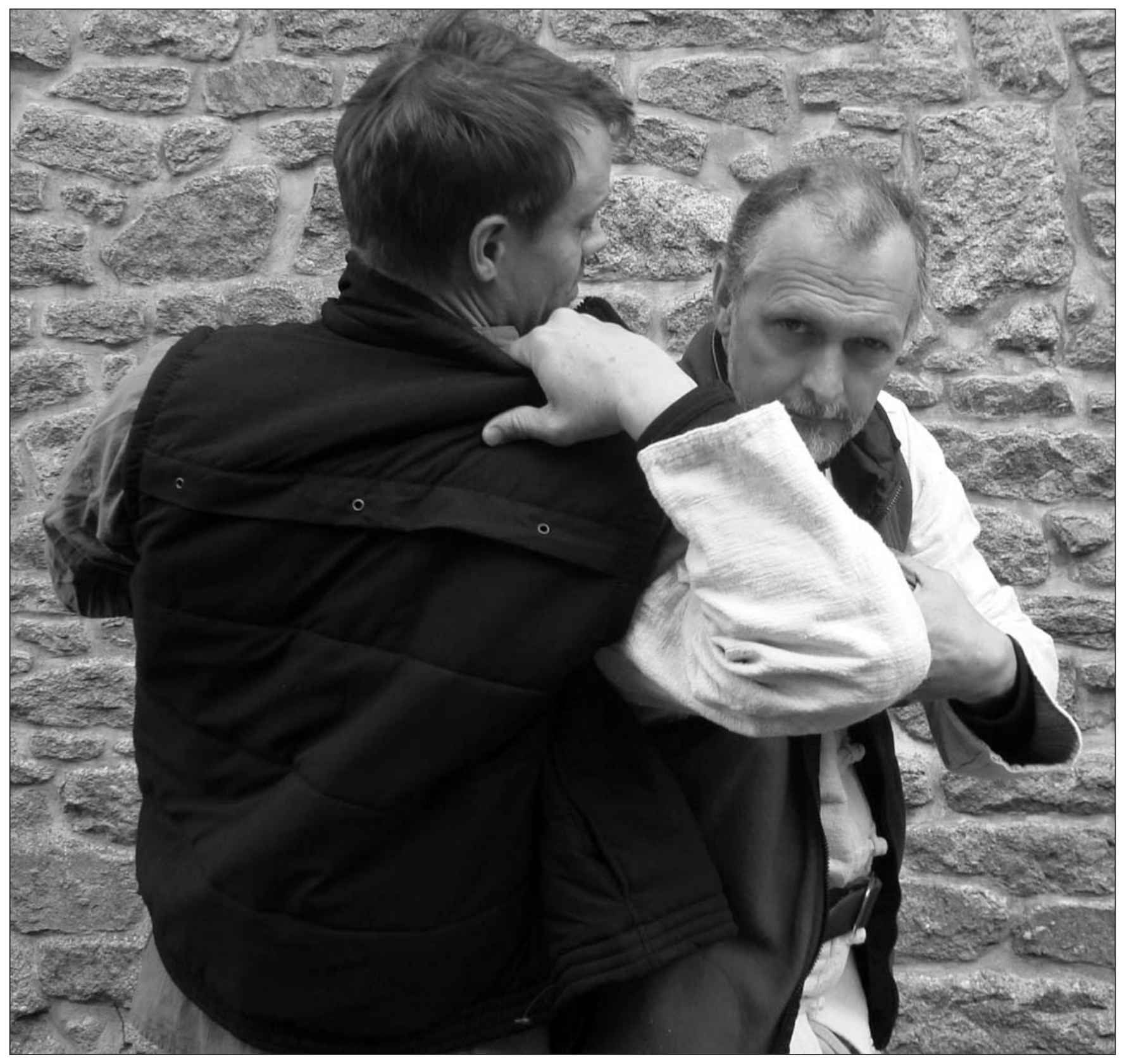

ARRIBA: Resumen

El AUTOR (DERECHA) y su El desarrollo de las artes de combate comienza por los principios universales de la anatomía AYUDANTE ERWAN CLOAREC PRACTICANDO VARIANTES DE LA PROYECCIÓN DE HOMBRO. humana. Como resultado, en cada cultura encontramos técnicas de combate que comparten las mismas tácticas y aplicaciones. Además, muchas técnicas han viajado a través de las culturas. Por ilustrar simplemente una táctica marcial y su presencia a nivel mundial entre las artes de combate, este artículo presenta las variaciones de la proyección de hombro que se encuentra en Persia, Grecia, Japón, China, Inglaterra y Francia. Así, encontramos dos métodos principales en la proyección de hombro, donde el defensor se mueve hacia dentro o hacia fuera del brazo principal del atacante. Las variaciones técnicas parecen ser infinitas, ya que el defensor no sólo puede proyectar al oponente, sino que también puede emplear luxaciones, fracturas e incluso armas en las técnicas. Una comprensión académica y/o el aprendizaje práctico de estas técnicas transculturales aportan un mayor entendimiento de las artes marciales en general, así como un componente práctico para aquellos que aprenden las habilidades para su aplicación práctica. 


\title{
UNA TÁCTICA MARCIAL UNIVERSAL: LA PROYECCIÓN DE HOMBRO Y SUS VARIANTES
}

\author{
Allen Pittman (cer
}

\author{
"Hay un momento para todo y \\ un tiempo para cada cosa bajo el sol" \\ $\sim$ Eclesiastés, 3:1
}

\section{Introducción}

Existen tácticas marciales que son comunes a todas las culturas. Realizaremos una breve descripción de los escitas como ejemplo. Eran un puente viviente entre las culturas orientales y occidentales. Las evidencias indican que cruzaron a Europa Occidental desde el norte de Persia sobre el año 1180 a.C., y después regresaron nuevamente en dos olas migratorias más. Las leyendas que portaron los escitas -muy probablemente derivadas del Shahnamah (Libro de los Reyes) persa- estaban repletas de conceptos alusivos a la caballería que más tarde inspirarían las leyendas del Rey Arturo (Ferdowsi, 2006). La copa, la espada o la lanza sagradas, o el "cuerno de la abundancia" o grial, todas ellas encuentran su más temprano fundamento en las leyendas escito-persas (Littleton \& Malcor, 2000).

Los escitas eran nómadas y expertos arqueros y jinetes. Precediendo a los mongoles, mostraban muchas de sus mismas virtudes militares de extrema movilidad, solidaridad grupal y adaptabilidad (Poliakov, 1995). También eran conocidos por ser improvisadores sumamente eficaces con las armas que capturaban de otras culturas. Sus túmulos tienen los mayores almacenes de armas de cualquier pueblo (Rolle, 1989). Como un prisma, la cultura escita refleja muchas tácticas marciales de otras culturas, tanto orientales como occidentales.

En nuestra era, muchos estudiantes de artes marciales modernas se encuentran a sí mismos en una posición similar a la de los escitas, teniendo a su disposición todo tipo de técnicas y armas de oriente y occidente. ¿Cómo podemos priorizarlas para nuestros estudios y usos? En la convergencia de estas numerosas técnicas, tanto físicas como mentales, solemos encontrarnos con que el cuerpo humano, en sí mismo, es el medio definitorio. Las variables básicas de tamaño corporal, predisposición del oponente y arma específica se convierten en los factores determinantes en el momento existencial. Cuando se considera desde este punto de vista, lo que surge es un grupo fundamental de tácticas, siendo una de ellas la proyección de hombro. 


\section{La proyección de hombro y sus variantes}

Actualmente, en todo el mundo se están gastando ingentes cantidades de dinero en la fabricación de misiles. El misil no es en sí mismo nada más que una flecha tecnológicamente avanzada. En esencia, la flecha es una lanza con un mecanismo de lanzamiento mecánico, y la lanza es una extensión del brazo humano, afilada, más fuerte y menos vulnerable al daño. La esencia del combate es alcanzar al oponente del mismo modo que lo hace una flecha, una lanza, o un misil "llegando al objetivo", mientras que se espera que el oponente no te alcance. Cuando nos estiramos para golpear o agarrarnos, utilizamos la quintaesencia de la técnica marcial, que es tomar el control o herir al oponente. Hay muchas articulaciones del brazo que pueden conseguir este "objetivo", además de distintas maneras de golpear con o sin un arma, y estas componen las técnicas básicas de ataque durante el combate.

Una de las respuestas defensivas más recurrentes frente al agarre o golpe a la parte superior del cuerpo (especialmente a la cabeza) es la proyección de hombro. Debido a su peligrosa naturaleza, la proyección de hombro no es utilizada en algunas formas rurales de lucha, como sucede en diversos estilos de "Back Hold" de la provincia de Cumberland en Inglaterra, o en la Lucha Bretona con Chaqueta de la Bretaña francesa (Longhurst, 2006). Sin embargo, aparece en la lucha tradicional de India e Irán, así como en la lucha libre de Occidente, e incluso existen variantes en la llamada "Lucha Greco-Romana" (que en realidad es la lucha persa sin agarres a la parte inferior del cuerpo, y que no tiene nada que ver con la tradición griega) donde uno necesita manejar el/los brazo/s en una posición práctica para obtener el efecto deseado. La proyección de hombro esta muy desarrollada en el judo y en el jujutsu tradicionales. Se encuentra en algunas formas de gongfu Shaolin chino, e incluso se practica en el llamado arte marcial chino "interno" del Bagua. Han Qingtan (b. 1900) enseñaba una variante de esta técnica como una de las técnicas básicas de luxación (qinna).

La proyección de hombro es básicamente un giro del torso mientras se sujeta el brazo del oponente. La técnica se modifica al aplicarla al lado interior o exterior del brazo principal del oponente. Por ejemplo, un puñetazo parecido al gancho de un boxeador le permite a uno moverse dentro de la posición del atacante (Fig. 1), pero para una acción con el reverso de la mano resulta más fácil moverse hacia fuera (Fig. 2). La dirección que se decida depende en gran parte del ángulo del codo que mantenga el brazo principal del atacante. La posición preliminar del codo es normalmente la posición "reveladora" que informa al defensor de qué lado del brazo principal parar, y de este modo decidir si moverse hacia el interior o el exterior del brazo.
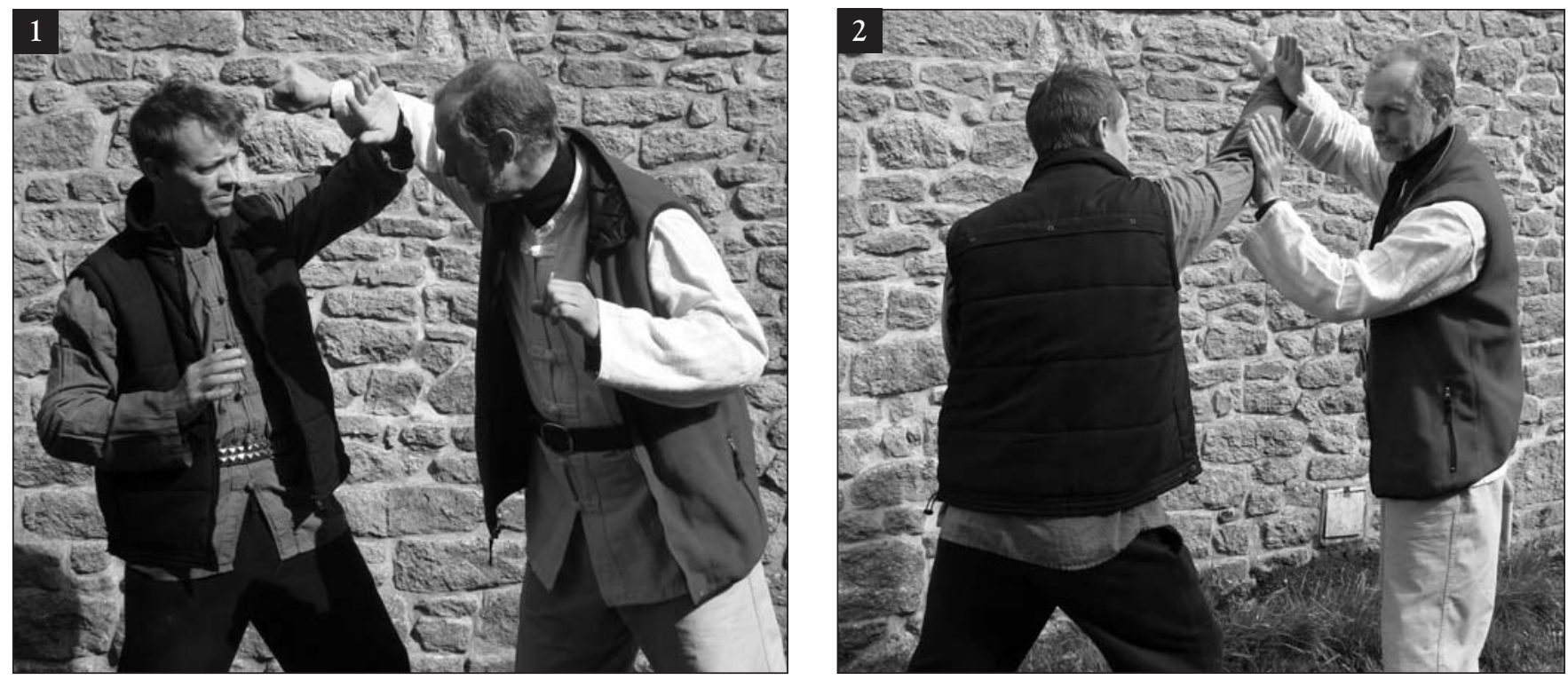
El jab directo es el más difícil de evaluar cuando se ejecuta, ya que hay poco que ver. Si el codo del atacante está apuntando hacia fuera, uno debería parar el brazo hacia el exterior y entrar, y esto tiene que realizarse en un movimiento simultáneo, acompasado con el ataque para evitar el golpe del brazo atrasado del atacante. Si el codo está señalando hacia abajo, uno puede parar con mayor facilidad el brazo hacia dentro, dar un paso hacia fuera, y prepararse para un movimiento hacia el exterior (Fig. 3).

En su forma más combativa, la proyección de hombro esta casi siempre precedida de un desvío o un desvío y un ataque (Figs. 4-5). Cuando se utiliza con un giro exterior, se puede romper el brazo principal a la altura del codo o dislocar el hombro. El antiguo arte griego muestra esto tanto en los frisos como en las estatuas (Fig. 6). Los antiguos escritos de Hipócrates, "Padre de la Medicina", realizan claras referencias a hombros dislocados de deportistas. Mucho más tarde, el médico pionero Galeno, llevó esta tradición al cuadrilátero gladiatorio y la mejoró. Esta es la proyección, especialmente hacia el exterior, que con mayor probabilidad dislocará el hombro. Un hombre en combate con un solo brazo funcional está definitivamente en desventaja, por no mencionar el dolor que le causará la dislocación. Además, la misma proyección también funciona para desarmar a un oponente armado.
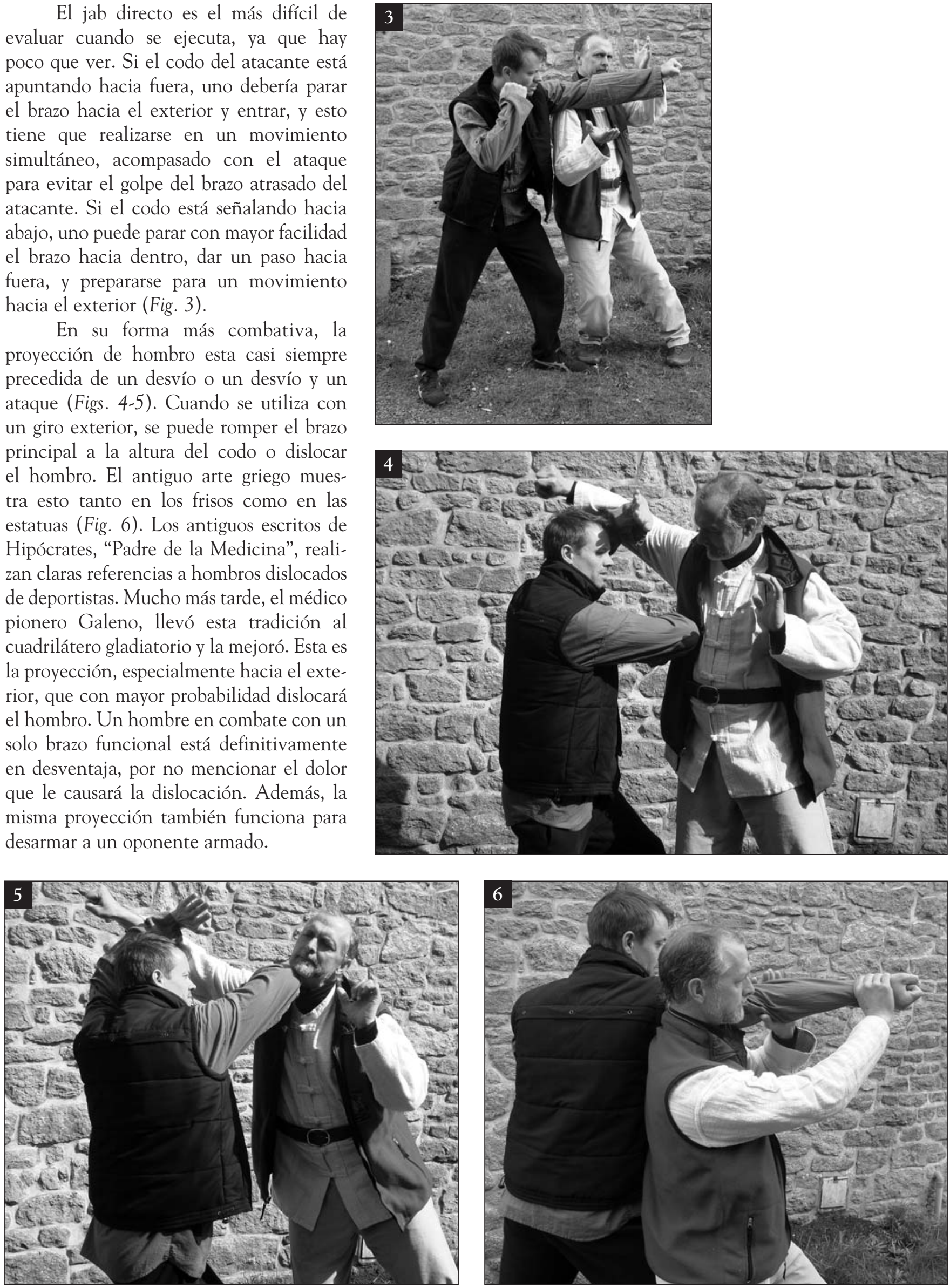

Revista de Artes Marciales Asiáticas $\diamond$ Volumen 4 Número 3 (90-101) - 2009 

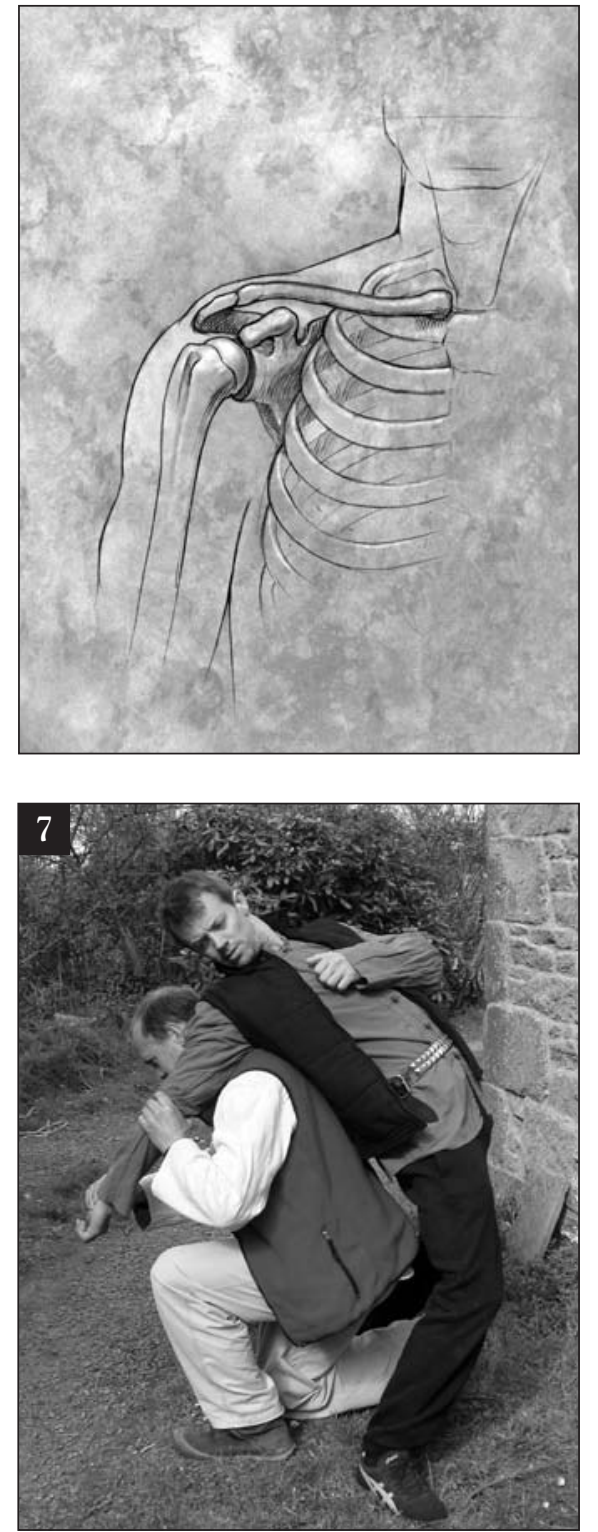

La estructura de la parte superior del brazo (húmero y escápula) forma una articulación poco profunda, no como la de la cadera que tiene una cuenca profunda. La superficialidad de esta articulación es su cruz y su bendición. Su cruz porque el brazo puede salirse de la escápula, y una bendición porque la superficialidad de esta articulación proporciona la extraordinaria amplitud de movimientos que necesitan los brazos.

Los antiguos griegos no sólo girarían su espalda durante el movimiento, sino que algunas veces también se arrodillaban. Esto coloca al hombro en posición para ser desplazado hacia delante o hacia la parte anterior del cuerpo. La unión del húmero con la escápula es especialmente vulnerable en este ángulo. Es parecido al ángulo del cuerpo cuando cae hacia atrás. Si pones tu mano hacia atrás para resistir la caída, el húmero puede salirse de la escápula debido al impacto.

La dislocación es especialmente probable si las espaldas de ambos están en contacto (Fig. 7). La dislocación también se facilita si se bloquea el codo. Tanto en el judo como en el jujutsu la preparación para la proyección - metiéndose bajo el brazo y hacia fuera- se utiliza como conexión en una secuencia de desarme, especialmente frente a cuchillo o espada.

Hacia el interior, vemos muchas de las aplicaciones del judo/jujutsu en las que el agarre a la ropa es muy importante (Figs. 8-9).
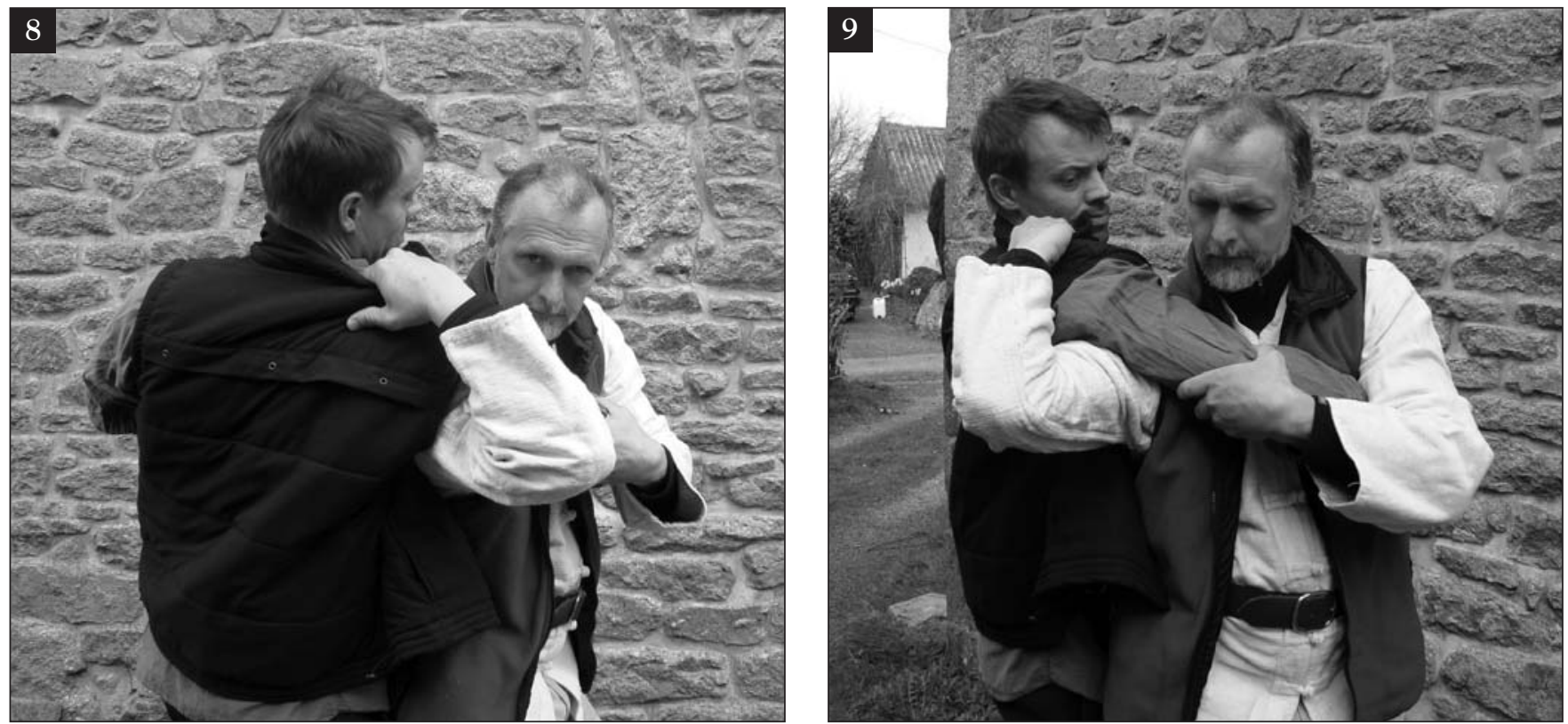
En el estilo baguazhang enseñado por Gao Yisheng en Tianjin, China, en la década de 1920 y más tarde llevado a Taiwán por Zhuang Junfeng, se utiliza la colocación por fuera del brazo en una secuencia de movimiento donde los mismos hombros se convierten en el punto de apoyo desde el que realizar la proyección alrededor del cuerpo con poco o ningún movimiento vertical. La proyección aquí se orienta preferentemente hacia un muro, como muestra la fotografía, o hacia otra persona (Figs. 10-11).

Hay dos aplicaciones fundamentales hacia el exterior del cuerpo del oponente: una es romper el brazo (dislocar el hombro o romper el codo), como en qinna o "dislocación del hueso" (i.e. el "Cerdo atado)" (Fig. 12) del Han Qingtan, y la otra es coger el brazo doblado (el doblar el brazo es una buena forma de evitar que el codo se rompa) hacia abajo y a través del cuerpo para completar la proyección (no mostrada).

Cuando se entra hacia el interior del cuerpo del oponente, un golpe previo con la cadera o con la rodilla dirigido a la entrepierna, o utilizar un golpe de codo al pecho, ayuda a evitar la actividad del brazo libre del oponente (Fig. 13). Como se ha afirmado, "Todas las proyecciones de judo funcionan en combate si primero golpeas a tu oponente".

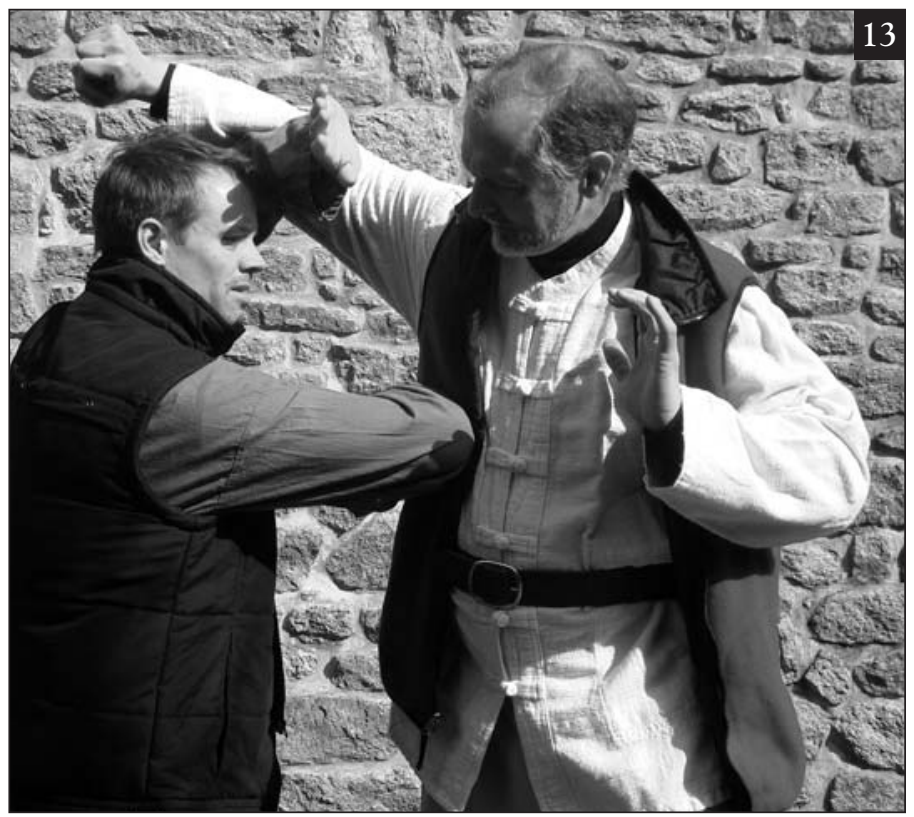

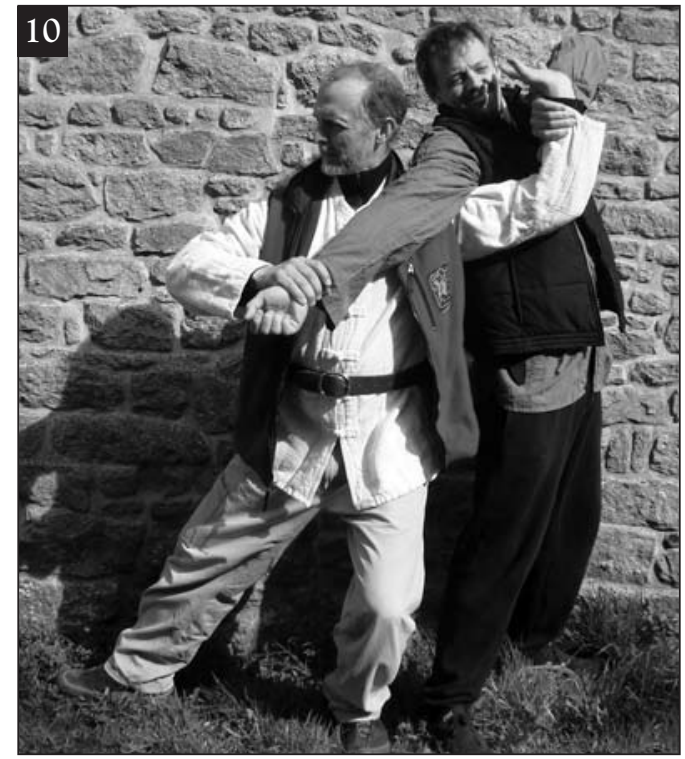
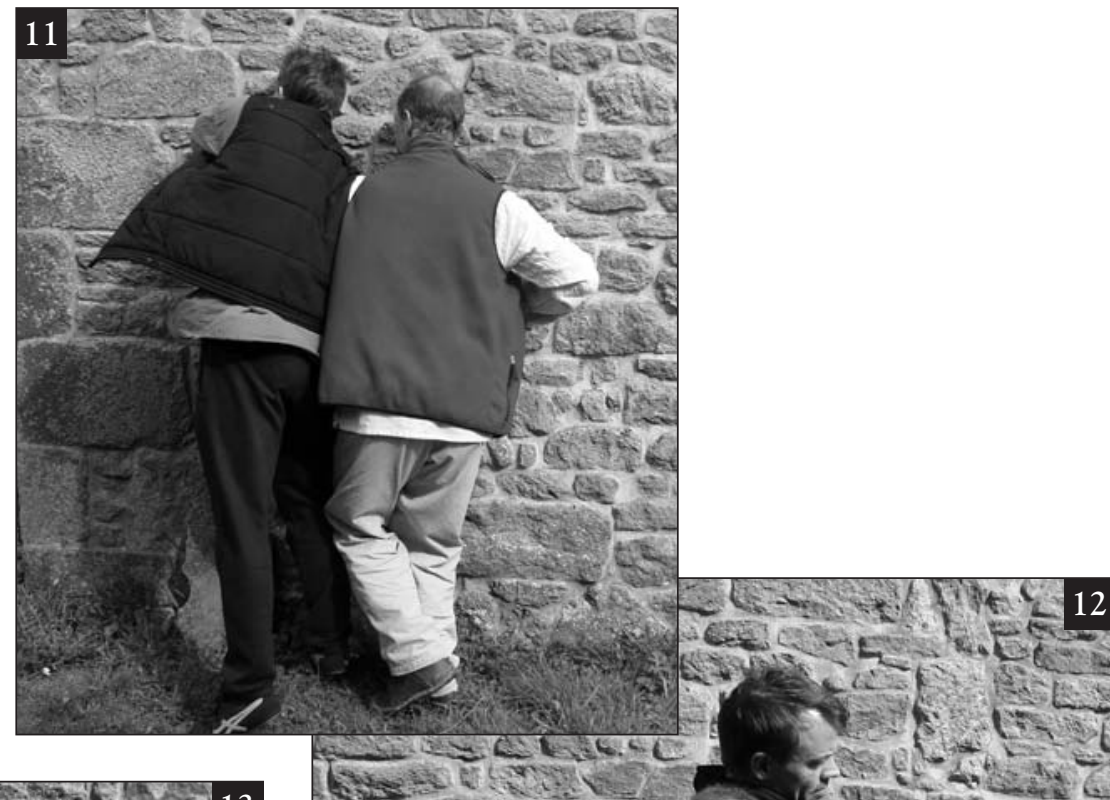
$-7+v^{2}+20$ किise en $-20$

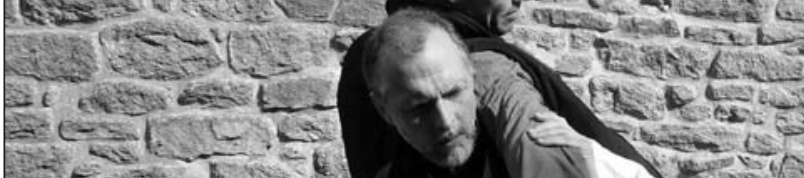

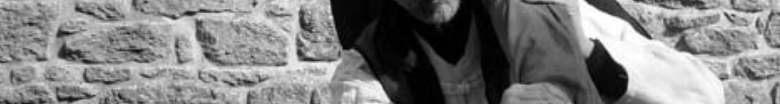

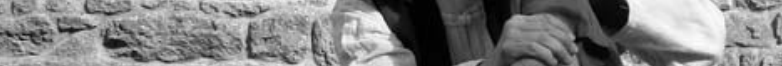

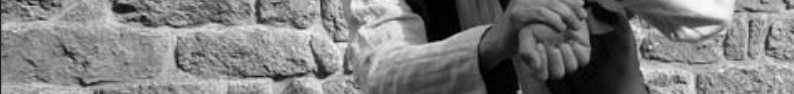

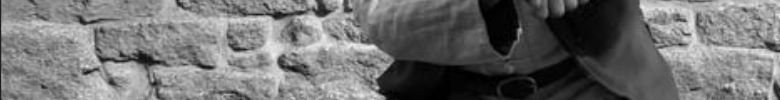

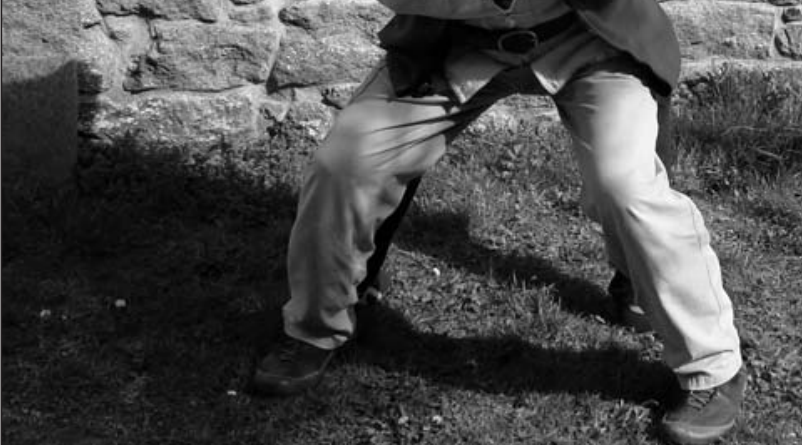


Después de una fase inicial de golpeo, como se muestra en la Figura 12, uno simplemente coge el brazo del oponente sobre el hombro, o bajo el mismo si es alto, y gira el cuerpo (Figs. 14-15). Cuando se da un paso hacia el exterior es importante controlar el codo del oponente, así como su mano, colocando correctamente las propias manos (Fig. 16). Este tipo de control permite una fácil continuación con una luxación en el suelo (Fig. 17).
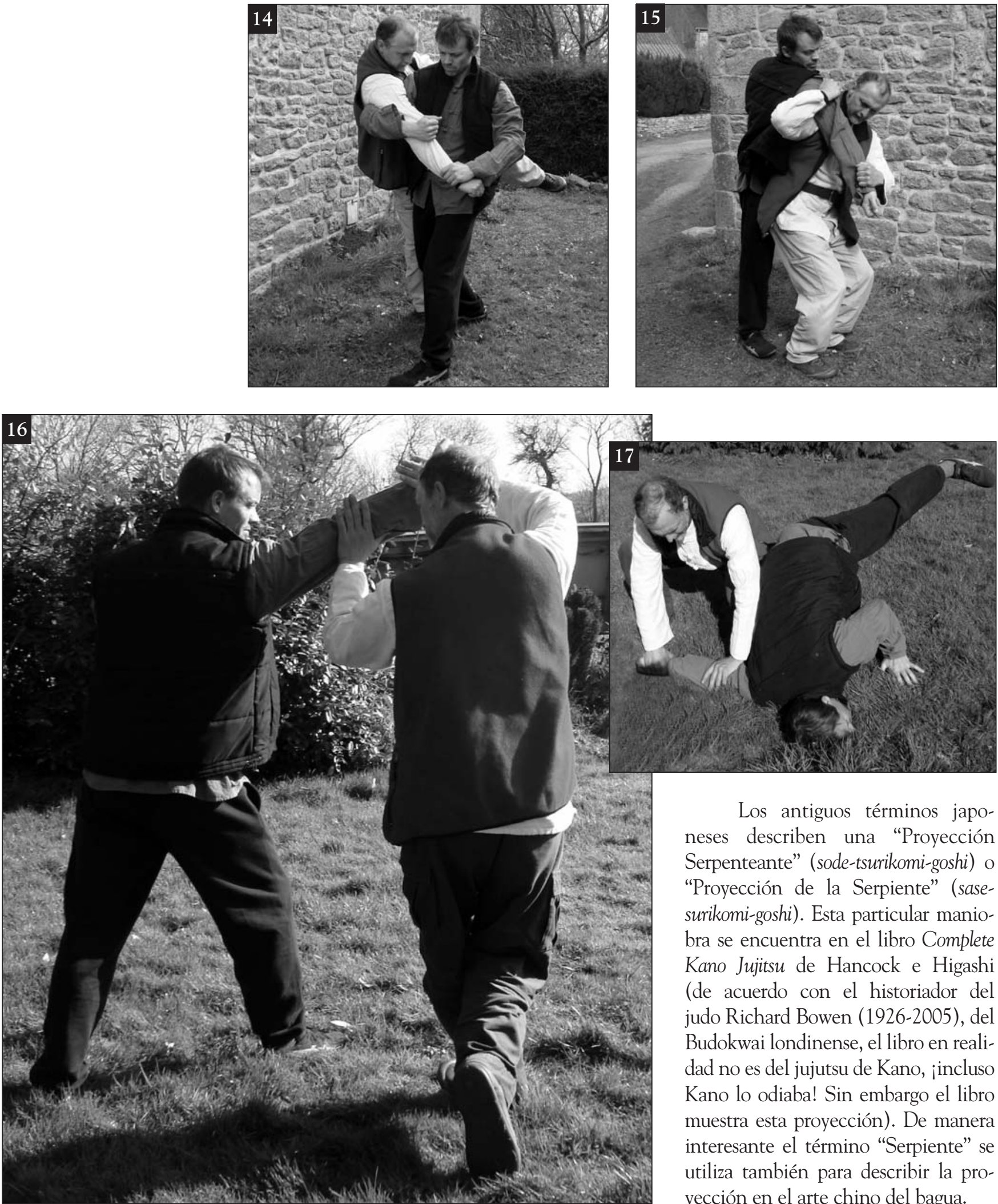

Los antiguos términos japoneses describen una "Proyección Serpenteante" (sode-tsurikomi-goshi) o "Proyección de la Serpiente" (sasesurikomi-goshi). Esta particular maniobra se encuentra en el libro Complete Kano Jujitsu de Hancock e Higashi (de acuerdo con el historiador del judo Richard Bowen (1926-2005), del Budokwai londinense, el libro en realidad no es del jujutsu de Kano, jincluso Kano lo odiaba! Sin embargo el libro muestra esta proyección). De manera interesante el término "Serpiente" se utiliza también para describir la proyección en el arte chino del bagua. 
Este tipo de proyección con envolvimiento del brazo es especialmente efectiva si el defensor tiene ambas muñecas cogidas o si se han agarrado las muñecas del oponente (Fig. 18) (el primer instinto si el oponente tiene un cuchillo en cada mano); sin cuchillo (Figs. 19-20); con un cuchillo (Figs. 21-23; en la 23 el brazo izquierdo de mi oponente está oculto -está cruzado delante del cuerpo, comprimido por mi hombro y espalda, mientras cojo su mano).
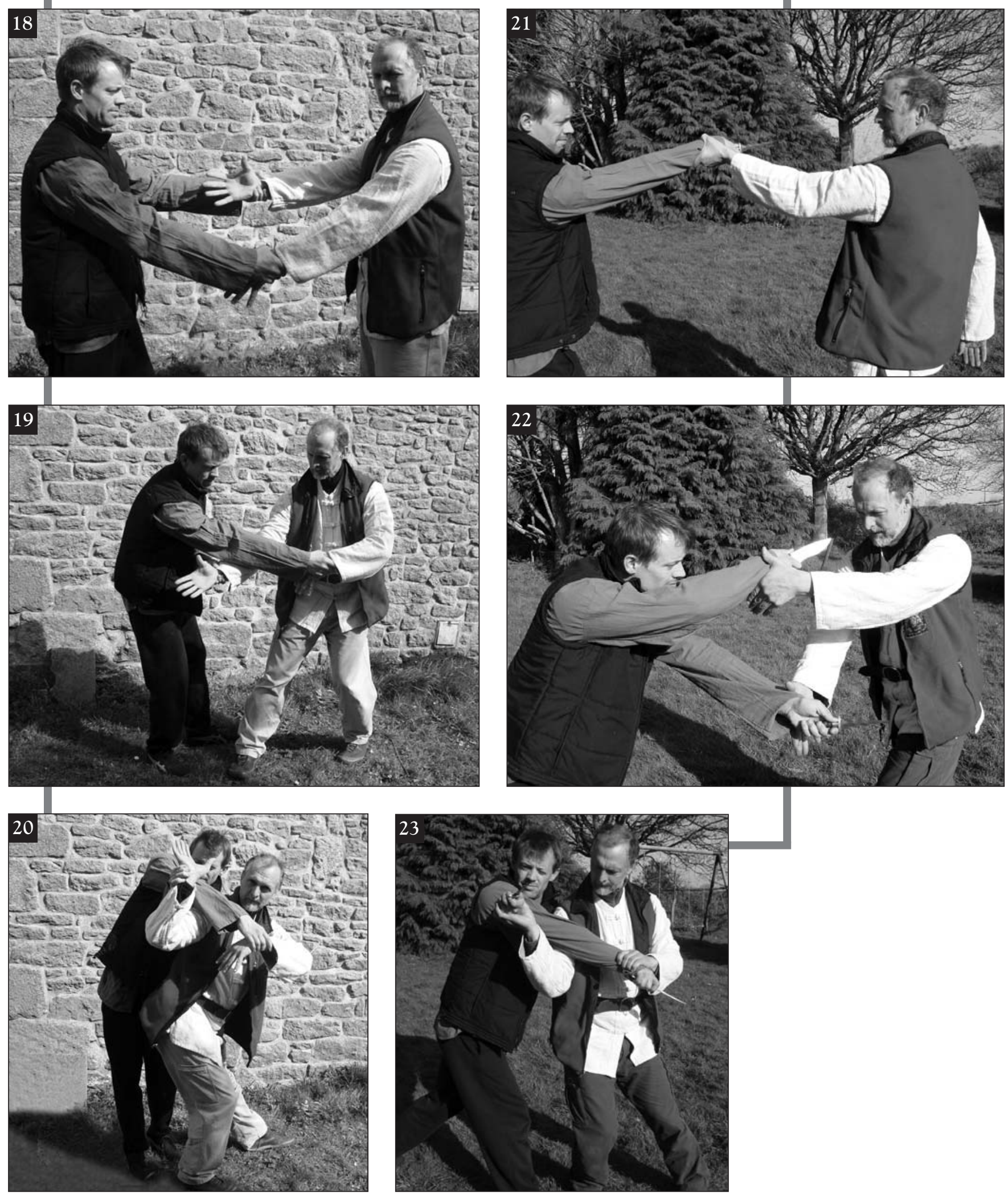

Revista de Artes Marciales Asiáticas $\diamond$ Volumen 4 Número 3 (90-101) - 2009 
La esencia de la proyección de hombro es la rotación o giro del cuerpo. Esto llega a ser incluso más evidente cuando aumenta la distancia entre los dos adversarios y uno tiene que prepararse o conseguir "estar listo" para utilizar la distancia y el impulso. Cuando se es atacado con un cuchillo, el momento crucial para determinar dónde se encuentra el filo y la punta en el espacio es al comienzo del movimiento. Cuanto más
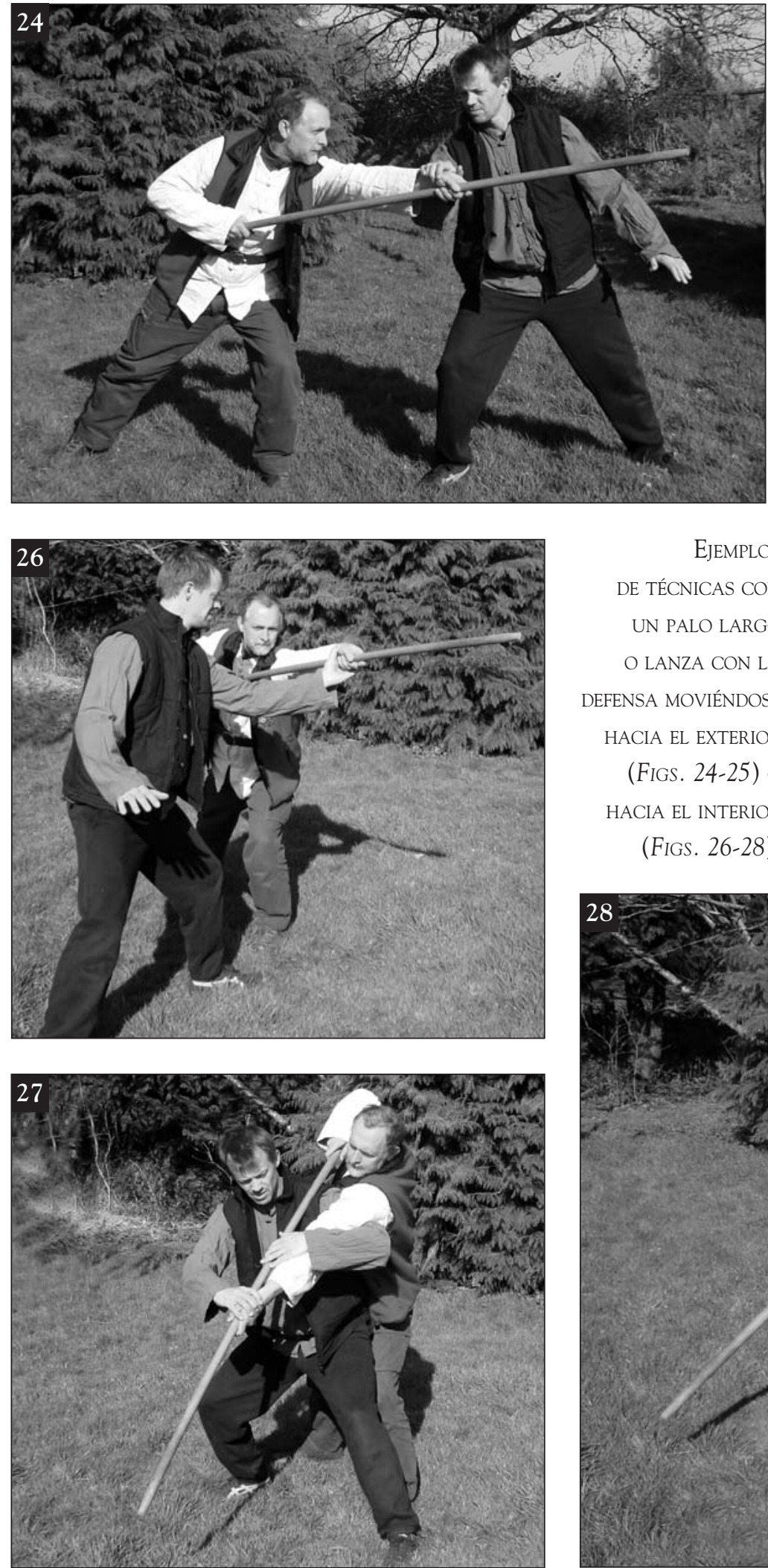
larga es el arma, más difícil será acercarse para realizar la proyección. Si tienes un arma de algún tipo, puedes utilizarla para acortar la distancia con un desvío. Si no tienes un arma, la siguiente mejor opción es lanzar un abrigo, arena o líquido a los ojos del oponente ( asumiendo que no tiene una pistola en sus manos!) para ganar tiempo mientras acortas
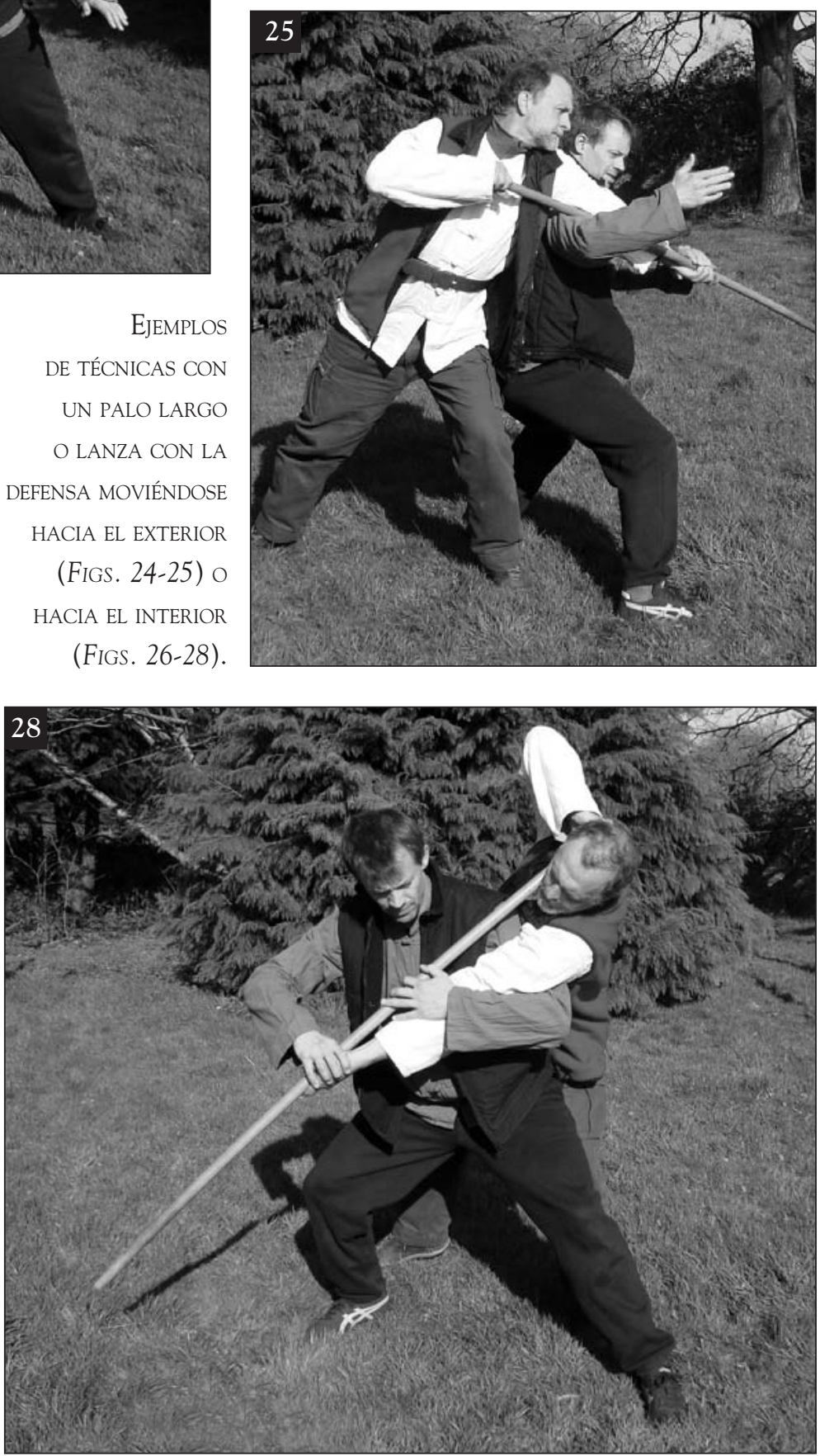
la distancia entre tú y el oponente antes de entrar a la proyección. Si el ataque es sin armas, el principal aspecto a evaluar es el brazo principal del oponente y la posición del codo. Puedes desviar la mano, pero querrás controlar el codo. Aquí, con el codo hacia el exterior, la postura te invita a ir hacia el interior (Figs. 29-30). Cuando el codo está hacia abajo, la postura invita a moverse hacia el exterior (Figs. 31-34).
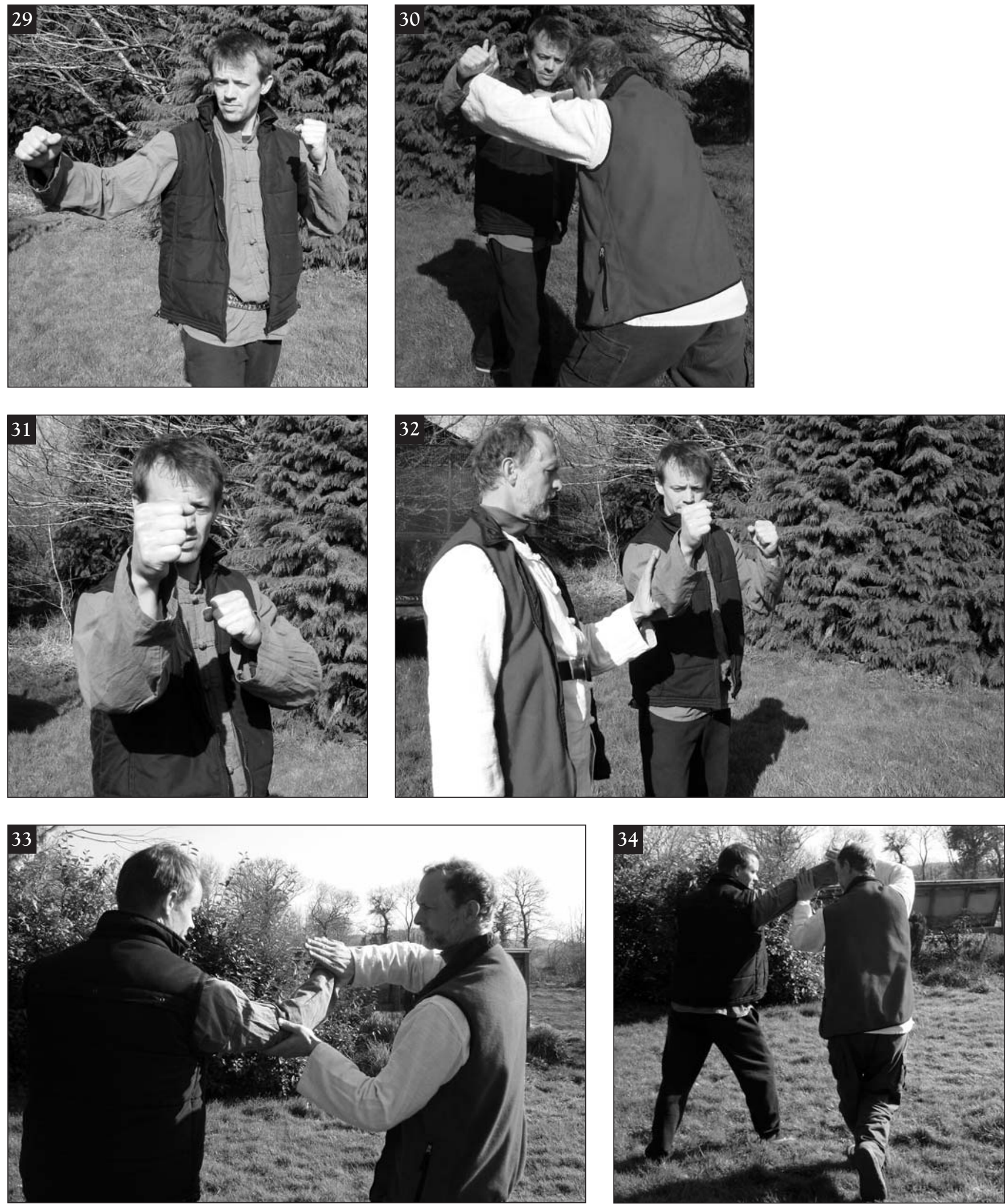

Revista de Artes Marciales Asiáticas $\diamond$ Volumen 4 Número 3 (90-101) - 2009 


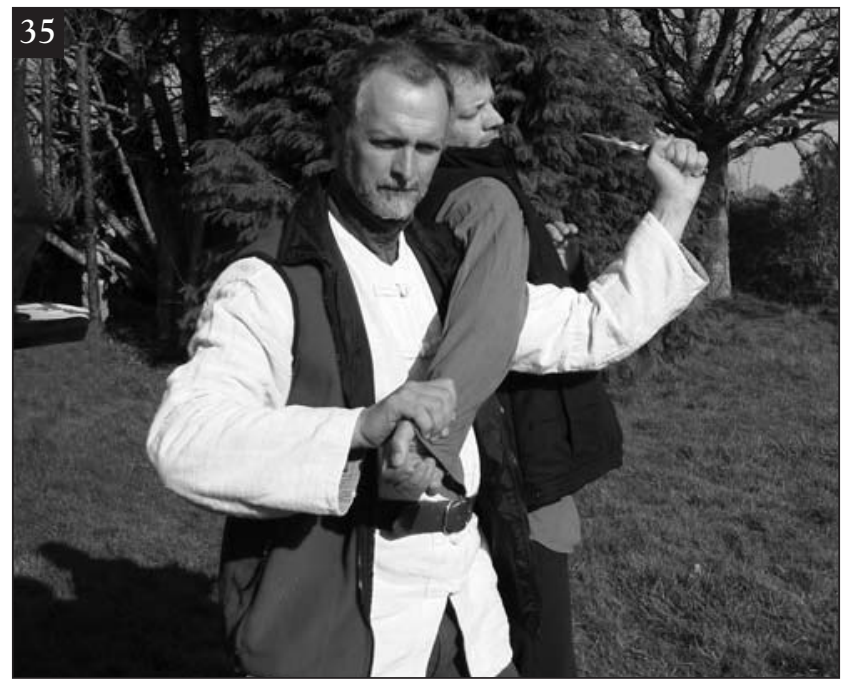

La altura del oponente también es crucial para la ejecución de la técnica. Si es alto, es mejor meterse bajo su brazo (Fig. 35). Si es bajo, muévete sobre el brazo utilizando el codo o el antebrazo para conseguir una reacción desde la cabeza mediante una finta, rozando o golpeando -punto en el cual la preparación para la "proyección de hombro" se convierte en realidad en proyección, utilizando la cabeza o el cuello, o una simple rotura del cuello-. Aquí hay ejemplos técnicos mostrados por el interior (Figs. 36-37), por el exterior (Figs. 38-40), y también una rotura del cuello al estilo Fairbairn (Fig. 41). En la obra All In Fighting (1942), William Fairbairn muestra esta posición simplemente como una forma de controlar el cuello, efectiva si se realiza lo suficientemente rápido, pero sin garantías de éxito si la persona tiene el cuello desarrollado de un luchador o es simplemente demasiado alto.
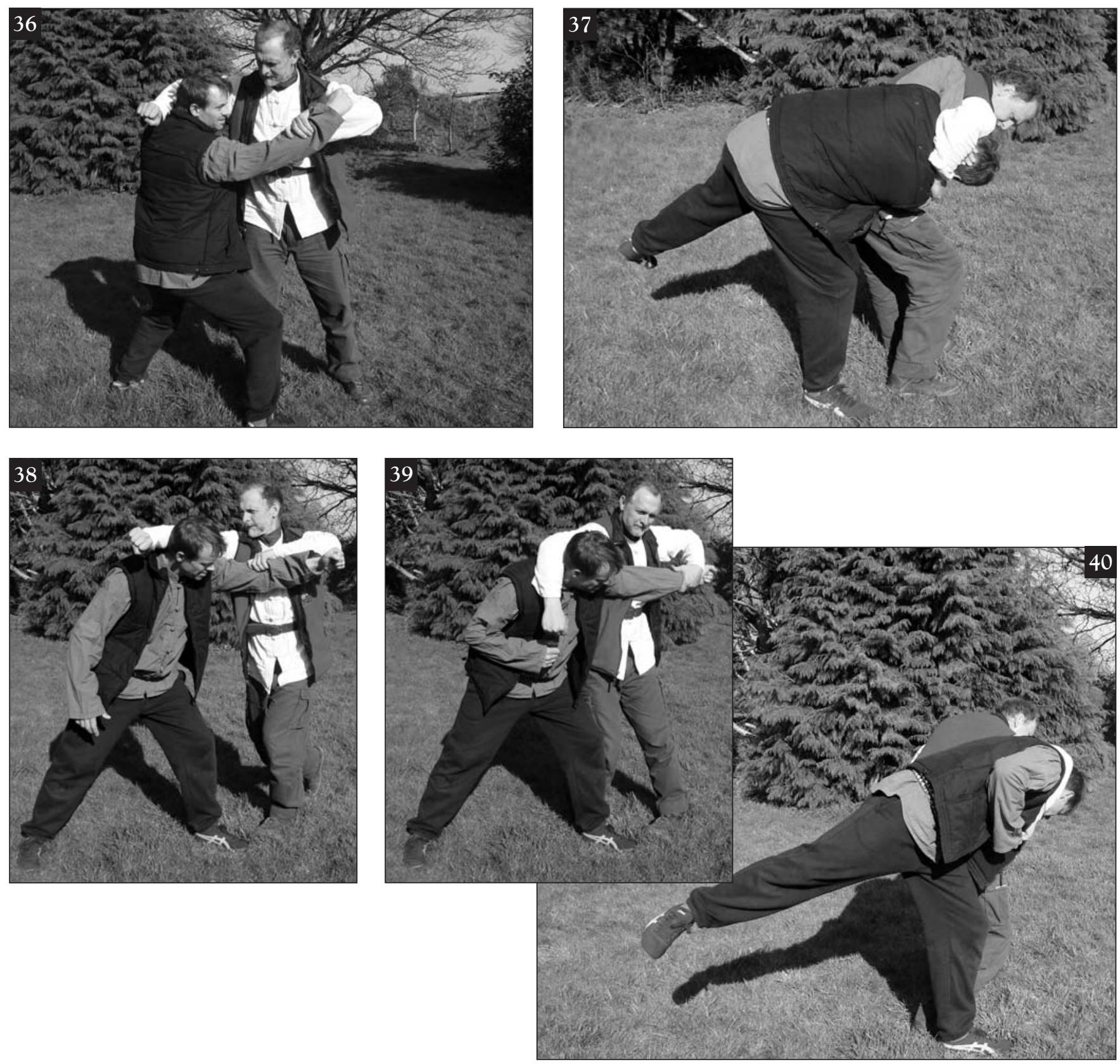


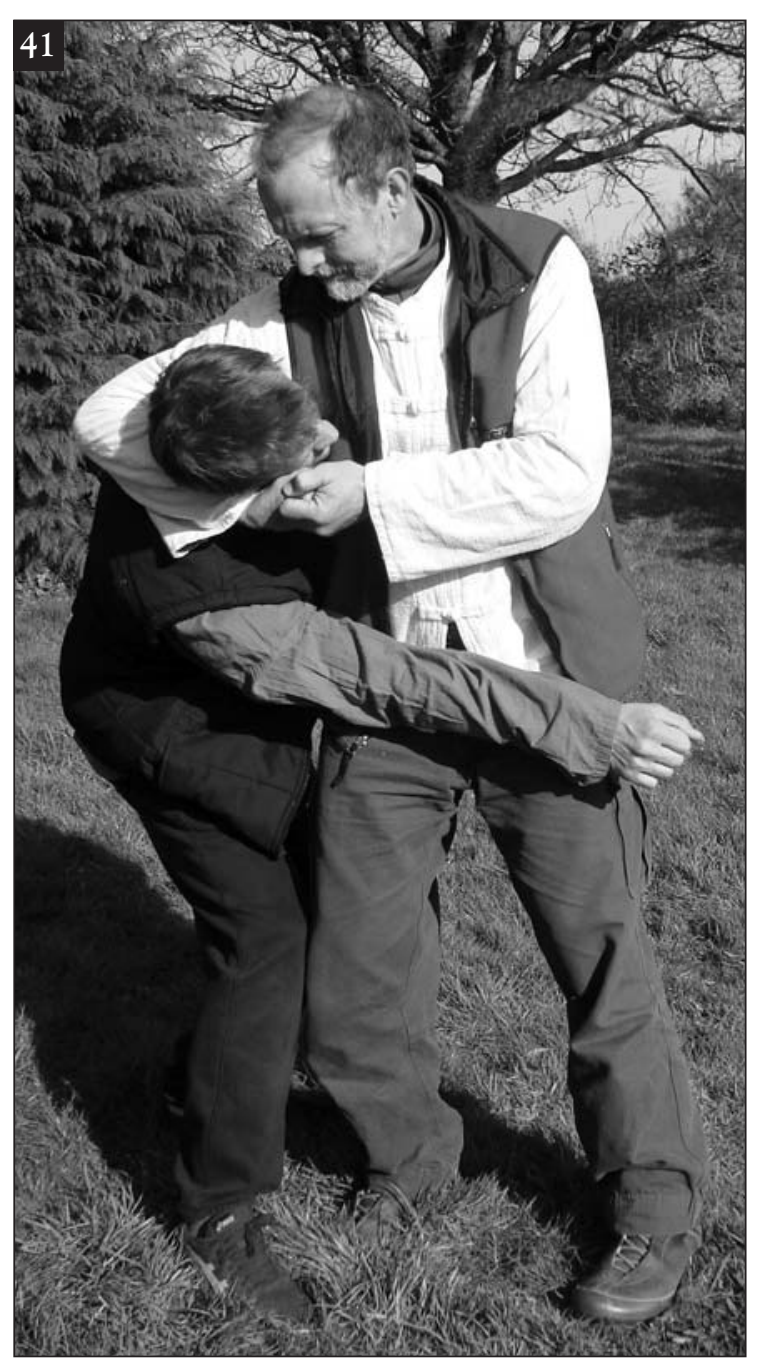

\section{Comentarios finales}

Las variaciones de la proyección de hombro mostradas en este artículo se encuentran en muchas tradiciones de combate, tanto de culturas orientales como occidentales. Puesto que fueron desarrolladas de acuerdo a la mecánica corporal, que es universal, comparten similitudes entre culturas, incluso cuando las técnicas particulares están asociadas habitualmente con pueblos o naciones concretas, como los persas, escitas, británicos, franceses, chinos y japoneses.

Con el acceso que actualmente tenemos a las tradiciones marciales compartidas a través de libros, seminarios, vídeos y DVDs, disponemos de un número nunca antes visto de tácticas marciales. Una comprensión académica y/o el aprendizaje práctico de estas técnicas transculturales aportan un mayor entendimiento de las artes marciales en general, así como un componente práctico para aquellos que aprenden las habilidades para su aplicación práctica.

\section{BIBLIOGRAFÍA}

FAIrbAirn, W. (1942). All in fighting. London: Faber and Faber.

Ferdowsi, A. (2006). Shahnameh: The Persian book of kings. D. Davis, Trad. New York: Viking.

Hancock, H. (2006). Complete Kano jujitsu. Mineola, NY: Dover Publications.

Littleton, C. \& Malcor, L. (2000). From Scythia to Camelot: A radical reassessment of the legends of King Arthur, the knights of the round table, and the Holy Grail. New York, NY: Routledge.

Longhurst, P. (1936/2006). How to coach wrestling. New Delhi: Sports Publication.

Poliakov, M. (1995). Combat sports in the ancient world: Competition, violence, and culture. New Haven, CT: Yale University Press.

Rolle, R. (1989). The world of the Scythians. Stanford, CA: University of California Press.

\section{AGRADECIMIENTO}

Con el debido respeto a mis profesores, el ahora difunto James 'Tim' Geoghegan (lucha celta, osteópata articular), Hong Yimian (estilo Gao de bagua, osteópata articular), y a Robert W. Smith (métodos qinna de Han Qingtan) por ofrecerme el material práctico que figura en el artículo. Un agradecimiento especial a mi ayudante Erwan Cloarec por posar para las secciones técnicas y a Victoria Slakey por la fotografía. 